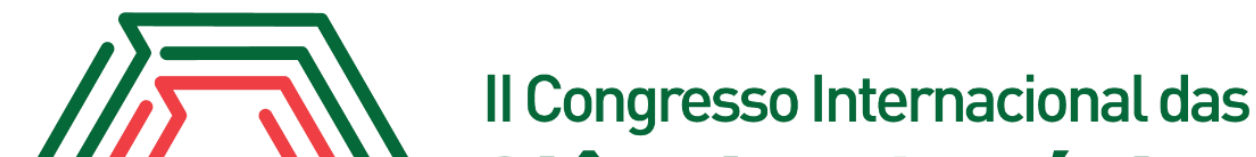 Ciências Agrárias COINTER - PDVAgro 2017
}

\section{COMPOSIÇÃO CENTESIMAL DE FENOS DE LEGUMINOSAS DA CAATINGA}

\author{
Apresentação: Pôster
}

Daniel Glaydson Farias Guerra ${ }^{1}$; Elaine Cristine Alves Soares ${ }^{2}$; Isaac Sydney Alves da Silva Maia $^{3}$; Hilton Felipe Marinho Barreto ${ }^{4}$, Alexandre Paula Braga ${ }^{5}$

\section{Introdução}

A produção de alimento para os animais constitui o maior problema para o desenvolvimento da pecuária no semiárido. No entanto, o planejamento alimentar adequado dos rebanhos faz-se necessário para o estabelecimento de estratégias de produção, aproveitamento de plantas forrageiras nativas em pleno vigor nutritivo, assim como a conservação através do armazenamento para fornecimento aos animais nos períodos de escassez. Fica claro que o desafio, especialmente em regiões semiáridas devido à dificuldade de produção de alimentos, é conseguir atender as exigências nutricionais dos animais (GUIM; SANTOS, 2008).

A estruturação de um suporte forrageiro que garanta reservas para o período seco e o conhecimento da flora nativa com potencial forrageiro irá permitir uma escala de produção com consequente melhoria na renda. Dentre as plantas forrageiras da caatinga, as leguminosas merecem destaque devido ao seu alto teor de proteína, a qual representa o ingrediente mais oneroso nas rações fornecidas aos animais.

Este trabalho teve por objetivo avaliar a composição centesimal do feno de Jucá (Caesalpinia ferrea Mart.), Canafístula (Senna martiana Benth.) e do Feijão-de-Rola (Macroptilium lathyroides L.).

\section{Fundamentação Teórica}

\footnotetext{
${ }^{1}$ Graduando do curso de Zootecnia, Universidade Federal Rural do Semi-Árido (UFERSA), danielglaydson@hotmail.com.

${ }^{2}$ Mestranda do Programa de Pós-Graduação em Produção Animal (PPGPA), UFERSA, elainesoares01@yahoo.com.br.

${ }^{3}$ Msc em Produção Animal, UFERSA, isaacsydney@gmail.com.

${ }^{4}$ Professor Doutor, Instituto Federal de Educação, Ciência e Tecnologia do Rio Grande do Norte (IFRN) - Campus Apodi, felipebarreto.ifrn@gmail.com.

${ }^{5}$ Professor Doutor, UFERSA, apbraga@ufersa.edu.br.
} 
A caatinga é um bioma exclusivo do Brasil que ocupa todo o Nordeste e uma porção do norte do estado de Minas Gerais (IBAMA, 2014), apresenta características de climas secos e quentes, possuindo duas estações bem definidas: a estação seca e a estação chuvosa. Botanicamente, a caatinga é constituída de muitas espécies de leguminosas lenhosas, sendo elas caducifólias, e de espécies herbáceas, que normalmente são anuais (CÂNDIDO, 2005). A caatinga possui grande importância dentro da pecuária nordestina, pois as espécies como o Jucá (Caesalpinia ferrea Mart.), a Canafístula (Senna martiana Benth.) e o Feijão-de-Rola (Macroptilium lathyroides L.) possuem alto valor proteico e servem de alimento para caprinos, ovinos e bovinos.

Uma técnica que é utilizada por diversos produtores para conservação de forragens é a fenação. Como o próprio nome já diz, a leguminosa quando fenada, conserva suas qualidades nutricionais, o que permite, na época de estiagem, esse alimento conservado ser fornecido aos animais.

\section{Metodologia}

O trabalho foi realizado na Universidade Federal Rural do Semi-Árido - RN, sendo as plantas estudadas coletadas nas cidades de Angicos, Apodi e Mossoró, localizadas no Rio Grande do Norte. As plantas foram colhidas em seu período vegetativo, antes da floração, e, em seguida, foram expostas ao sol e reviradas até que se apresentassem desidratadas, atingindo o ponto de feno.

O material fenado foi moído em moinho estacionário tipo Wiley, com peneira de $1 \mathrm{~mm} \mathrm{e}$ acondicionados em recipientes plásticos devidamente identificados. Posteriormente, o material triturado foi submetido à análise de composição centesimal para determinação dos teores de matéria seca (MS), matéria mineral (MM), proteína bruta (PB) e extrato etéreo (EE) conforme as recomendações de Silva e Queiroz (2002). Os valores da fibra em detergente neutro (FDN) e da fibra em detergente ácido (FDA) foram obtidos através da metodologia descrito por Van Soest (1963) e Van Soest (1967), respectivamente. E para a determinação do NDT foi utilizada a equação proposta pelo NRC (2001), conforme segue:

(1) $\mathrm{NDT}=\mathrm{PBD}+(2,25 \mathrm{x}$ AGD $)+\mathrm{FDNpD}+\mathrm{CNFD}-7$, em que o valor 7 se refere ao NDT fecal metabólico.

A determinação dos teores de proteína bruta digestível (PBD), ácidos graxos digestíveis (AGD), fibra em detergente neutro livre de proteína digestível (FDNpD) e carboidratos não fibrosos digestíveis (CNFD) seguiram as seguintes equações: 
(2) PBD (para alimentos volumosos) $=\mathrm{PB} \times\left(\mathrm{e}^{-1,2 \times \mathrm{PIDA} / \mathrm{PB}}\right)$, em que a proteína insolúvel em detergente ácido (PIDA), foi determinada submetendo as amostras de FDA a extração do nitrogênio, obtendo o nitrogênio insolúvel em detergente ácido (NIDA) e multiplicando por 6,25.

(3) $\mathrm{AGD}=(\mathrm{EE}-1)$; Fórmula expressa para de EE superior a 3\% na MS.

(4) $\mathrm{CNFD}=0,98 \times \mathrm{CNF} \times \mathrm{PAF}$, em que $\mathrm{CNF}=100-(\mathrm{MM}+\mathrm{PB}+\mathrm{EE}+\mathrm{FDNcp})$, e PAF, fator de ajuste para processamento físico, considerando valores de 0,92, 0,94, 1,04 e 1,0, respectivamente, para grão de sorgo, silagem de milho, farelo de cereais e demais alimentos.

(5) $\mathrm{FDNpD}=0,75(\mathrm{FDNp}-\mathrm{LDA}) \times\left[1-(\mathrm{LDA} / \mathrm{FDNp})^{0,667}\right]$, em que LDA é lignina em detergente ácido.

\section{Resultados e Discussões}

Os teores de matéria seca (MS), matéria orgânica (MO), matéria mineral (MM), extrato etéreo (EE), proteína bruta (PB), proteína insolúvel em detergente neutro (PIDN), proteína insolúvel em detergente ácido (PIDA), fibra em detergente neutro (FDN), fibra em detergente ácido (FDA), lignina (LIG) e nutrientes digestíveis totais (NDT) dos fenos das plantas estudas estão apresentados na Tabela 1.

Tabela 1: Composição centesimal com base na matéria seca (MS) dos fenos de Jucá, Canafístula e Feijão-de-Rola.

\begin{tabular}{lccccccccc}
\hline \multicolumn{1}{c}{ Plantas } & MS $^{1}$ & EE & PB & NDT & FDN & FDA & PIDN & PIDA & LIG \\
\hline Jucá & 88,90 & 4,40 & 12,90 & 68,40 & 44,20 & 31,80 & 2,50 & 2,00 & 10,40 \\
Canafístula & 92,10 & 4,70 & 14,10 & 77,60 & 39,20 & 24,90 & 4,70 & 2,10 & 4,00 \\
Feijão-de-Rola & 90,78 & 3,50 & 11,70 & 68,20 & 53,70 & 38,90 & 5,70 & 3,20 & 8,00 \\
\hline
\end{tabular}

Fonte: Própria

Legenda: $\mathrm{MM}=$ Matéria mineral, $\mathrm{EE}=$ Extrato etéreo, $\mathrm{PB}=$ Proteína bruta, PIDN = Proteína insolúvel em detergente neutro, PIDA = Proteína insolúvel em detergente ácido, FDN = Fibra em detergente neutro, FDA = Fibra em detergente ácido, LIG = Lignina e NDT $=$ Nutrientes digestíveis totais.

$1 \%$ da Matéria Natural.

A MS dos fenos (Tabela 1) demonstra que os materiais foram armazenados com teores de umidade adequados, uma vez que Evangelista e Lima (2013) aponta que o bom feno deve ter teor de MS acima de $82 \%$. Esses teores de MS permitem garantir menores perdas de nutrientes pela fermentação, além de evitar a formação de fungo e bolores, indicando adaptabilidade da planta forrageira ao processo de fenação. Os valores encontrados nesse trabalho estão muito próximos aos obtidos por Silva et al. (2010) para os fenos de Flor-de-Seda e Sabiá, que encontraram valores de 91,4 e $92,3 \%$, respectivamente. 
Os fenos estudados apresentaram bons teores de proteína bruta (Tabela 1), estando, os mesmos, acima do valor mínimo recomendado à produção animal. Valores inferiores a 7\% implicam em redução da digestibilidade e na ingestão de MS devido a inadequados níveis de nitrogênio para a manutenção dos microrganismos do rúmen (MILFORD e MINSON, 1966). Costa et al. (2012), trabalhando com os fenos de leguminosas arbóreas, obtiveram para a proteína bruta os resultados de 9,4; 14,4 e 16,7\% para os fenos de Catingueira, Jurema Preta e Leucena, respectivamente.

Os teores de FDN dos fenos analisados (Tabela 1) apresentaram-se dentro do esperado para uma forragem, uma vez que valores superiores a 55\% podem limitar o consumo de volumosos, reduzindo o consumo de forragem. A FDA encontrada nos fenos (Tabela 1) está dentro dos limites estabelecidos por Van Soest (1994) que estabelece como limite superior valor de 40\%, pois valores superiores implicam em baixa disgestibilidade do alimento, e como limite inferior ao valor de $28 \%$, que representa o mínimo de fibra na dieta de ruminantes para manutenção do funcionamento do trato gastrointestinal.

A quantidade de proteína insolúvel foi maior no feno confeccionado com Feijão-de-Rola (Tabela 1) em relação aos demais, tanto para a PIDN quanto para a PIDA. Em contrapartida, o feno de Canafístula foi o que apresentou os menores resultados. Os teores de PIDN e PIDA estão relacionados à disponibilidade da proteína sendo que quanto maior o valor dessa fração, menor o teor de nitrogênio disponível para o animal. A PIDA contém a proteína associada a lignina, taninos e compostos de Maillard altamente resistentes a degradação microbiana e enzimática, sendo-a considerada inaproveitável, tanto no rúmen como no intestino (SNIFFEN et al., 1992).

$\mathrm{O}$ teor de EE dos fenos ficou abaixo dos 5\%, máximo recomendado para dietas dos ruminantes, pois acima desse valor começa a ocorrer redução do consumo de MS. Os lipídios possuem 2,25 vezes mais conteúdo energético que os carboidratos, podendo aumentar a produção dos animais ruminantes quando usado de forma adequada (MORGADO, 2011).

\section{Conclusões}

Os fenos estudados apresentaram teores de nutrientes adequados à utilização na dieta de ruminantes.

\section{Referências}

CÂNDIDO, M. J. D.; ARAÚJO, G. G. L.; CAVAlCANTE, M. A. B. Pastagens no ecossistema 
Semi-Árido Brasileiro: atualização e perspectivas futuras. In: Reunião Anual da Sociedade Brasileira de Zootecnia, 2005, Goiânia, Anais... Goiânia: SBZ, 2005.

COSTA, M. R. G. F.; CARNEIRO, M. S. S.; PEREIRA, E. S.; et al. Utilização do feno de forrageiras lenhosas nativas do Nordeste brasileiro na alimentação de ovinos e caprinos. PUBVET, Londrina, V. 5, N. 7, Ed. 154, ART. 1035, 2012.

EVANGELISTA, A.R.; LIMA, J.A. Produção de feno. Informe Agropecuário, v.34, n.277, p.43$52,2013$.

GUIM, A.; SANTOS, G. R. A. MANEJO NUTRICIONAL DE PEQUENOS RUMINANTES EM REGIÕES SEMIÁRIDAS. In: CONGRESSO BRASILEIRO DE ZOOTECNIA, 18, 2008, João Pessoa. Anais... João Pessoas: Congresso Brasileiro de Zootecnia, 2008. p. 1 - 21.

INSTITUTO BRASILEIRO DO MEIO AMBIENTE E DOS RECURSOS NATURAIS RENOVÁVEIS - IBAMA. Ecossistemas Brasileiros: Caatinga. Disponível em: http://www.ibama.gov.br/ecossistemas/caatinga.htm, 2014.

MILFORD, R.; MINSON, D. J. Intake of tropical pasture species. In: CONGRESSO INTERNACIONAL DE PASTAGEM, 9, 1965, São Paulo. Anais... São Paulo: Secretária de Agricultura, 1966. p.814-22.

MORGADO, E. D. S. Óleo em dietas para ovinos alimentados com amido ou fibras solúveis em detergente neutro. 2011. 84 p. Tese (Doutorado em Zootecnia) - Universidade Estadual Paulista, Jaboticabal, 2011.

NATIONAL RESEARCH COUNCIL - NRC. Nutrient requirements of diary cattle. 7 ed. Washington, D.C.: National Academy Press, 2001. 381p.

SILVA, D. J.; QUEIROZ, A. C. Análises de alimentos: métodos químicos e biológicos. 2, ed. Viçosa, MG; UFV. 2002, 178 p.

SILVA, J.G.M.; LIMA, G.F.C.; AGUIAR, E.M.; MELO, A.A.S.; REGO, M.M.T. Cactáceas nativas associadas a fenos de flor de seda e sabiá na alimentação de borregos. Revista Caatinga, v. 23, n. 3, p. 123-129, 2010.

SNIFFEN, C. J.; O’CONNOR, J. D.; VAN SOEST, P. J.; FOX, D. G.; RUSSELL, J. B. A net carbohydrate and protein system for evaluating cattle diets. 2. Carbohydrate and protein availability. Journal of Animal Science, v. 70, n. 11, p. 3562-3577, 1992.

VAN SOEST, P. J. Nutritional ecology of the ruminant. New York: Cornell University Press, 1994. 476p.

VAN SOEST, P. J. Development of a comprehensive system of feed analysis and its application to forage. Journal Animal Science, v. 26, n. 1, p. 119-128, 1967.

VAN SOEST, P. J. Use of detergentes in the analysis of fibrous feeds. A rapid method for the determination of fiber and lignin. Journal of the Association Official Agricultural Chemists, v. 46, n. 5, p. 829-835, 1963. 